\title{
Overview of Helicobacter pylori Infection in Indonesia: What Distinguishes It from Countries with High Gastric Cancer Incidence?
}

\author{
Muhammad Miftahussurur ${ }^{1,2}$, Langgeng Agung Waskito², Kartika Afrida Fauzia², Isna Mahmudah², Dalla Doohan², \\ I Ketut Adnyana ${ }^{3}$, Ali Khomsan ${ }^{4}$, Neneng Ratnasari ${ }^{5}$, and Yudith Annisa Ayu Rezkitha ${ }^{2,6}$ \\ 1'Division of Gastroentero-Hepatology, Department of Internal Medicine, Faculty of Medicine-Dr. Soetomo Teaching Hospital, \\ Universitas Airlangga, ${ }^{2}$ Institute of Tropical Disease, Universitas Airlangga, Surabaya, ${ }^{3}$ Department of Pharmacology and Clinical \\ Pharmacy, School of Pharmacy, Institut Teknologi Bandung, Bandung, ${ }^{4}$ Department of Community Nutrition, Faculty of Human \\ Ecology, IPB University, Bogor, ${ }^{5}$ Department of Internal Medicine, Faculty of Medicine, Public Health and Nursing, Universitas Gadjah \\ Mada-Dr. Sardjito Hospital, Yogyakarta, and ${ }^{6}$ Faculty of Medicine, Muhammadiyah University of Surabaya, Surabaya, Indonesia
}

\section{Article Info}

Received January 12, 2020

Revised April 7, 2020

Accepted April 9, 2020

Published online July 6, 2020

Corresponding Author

Muhammad Miftahussurur

ORCID https://orcid.org/0000-0003-1415-6033

E-mail muhammad-m@fk.unair.ac.id

\begin{abstract}
Helicobacter pylori infects more than half the human population. However, the prevalence in Indonesia is low, as is the prevalence of gastric cancer. Hence, it could be instructive to compare these prevalence rates and their determining factors with those of countries that have high gastric cancer incidence. Ethnicity and genetic characteristics of $H$. pylori are important determinants of the $\mathrm{H}$. pylori infection rate in Indonesia. The infection rate is higher in Bataknese, Papuans and Buginese than in Javanese, the predominant ethnic group. Ethnicity is also an important determinant of the genetic characteristics of $H$. pylori. Analysis of CagA in the EPIYA segment showed that the predominant genotypes in Papuans, Bataknese and Buginese are ABB-, ABDand $A B C$-type CagA, respectively. Meanwhile, in the countries with high gastric cancer incidence, almost all strains had East Asian type CagA. An antibiotic susceptibility evaluation showed that the standard triple therapy can still be used with caution in several cities. There is a very high rate of resistance to second-line regimens such as levofloxacin and metronidazole. Recent studies have shown that furazolidone, rifabutin and sitafloxacin are potential alternative treatments for antibiotic-resistant $H$. pylori infection in Indonesia. Rather than focusing on early detection and eradication as in countries with high gastric cancer prevalence, countries with low gastric cancer prevalence should focus on screening the several groups that have a high risk of gastric cancer. (Gut Liver 2021;15:653-665)
\end{abstract}

Key Words: Helicobacter pylori; Indonesia; Cancer; Gastric cancer risk

\section{INTRODUCTION}

Helicobacter pylori is the most successful human pathogen and is associated with dyspepsia. It is also a common and curable cause of peptic ulcers and gastric cancer. ${ }^{1-3}$ The infection prevalence was high is many areas such as in Africa and East Asia which reported as $79.1 \%$ and $56.1 \%$ respectively. ${ }^{4}$ Despite their high prevalence, the gastric cancer incidence was varied. East Asian region has high age-standardized rates (ASR) of 22.4 and its countries Korea, Mongolia, and Japan were known for the highest gastric cancer incidence in the world with the ASR of 39.6,
33.1, 27.5, respectively. ${ }^{5}$ However, the African region has very low ASR; 4.2 per 100,000 people. On contrary, there was also region that have both low prevalence of $H$. pylori infection and low incidence of gastric cancer; such as a populous archipelago country, Indonesia. The investigation on this low prevalence either infection and gastric cancer incidence is also necessary as a comparison to find the risk factor and $H$. pylori properties that may contributes to infection and gastric cancer pathogenesis.

Indonesia is the fourth most populous country in the world, with $267,842,296$ people belonging to 300 ethnic groups in a total area of about $1,900,000 \mathrm{~km}^{2}$. Based on 
GLOBOCAN 2018, Indonesia was categorized as a low gastric cancer risk country with ASR of 1.22/100,000 (gco. iarc.fr). ${ }^{6}$ Our neighbor country, Malaysia was also reported to have low prevalence of $H$. pylori infection and low gastric cancer incidence (ASR of 5.2). Study in Malaysia reported that ethnicity play role in the $H$. pylori infection and gastric cancer and Malay ethnic is reported as low risk for gastric cancer compared to Chinese and Indian. Malay ethnic is also one of a large ethnic group in Indonesia. Indonesian's Malayan descent have low gastric mucosal severity, ${ }^{7,8}$ similar to that among Malayans in Malaysia and Singapore. ${ }^{9,10}$ Moreover, Indonesia consists of more ethnics that may provide more insight on the role of ethnicity and other factors.

H. pylori can damage epithelial cells and induce an inflammatory response, resulting in severe histopathology, suggesting that $H$. pylori should be eradicated even in populations with a low prevalence of $H$. pylori. ${ }^{11}$ Detecting the presence of $H$. pylori is critically important, and validation of the tests for $H$. pylori is required, especially in areas with a low prevalence of $H$. pylori. ${ }^{12}$ In Indonesia, urine tests have been validated with sensitivity of $83.3 \%$ and specificity of $94.7 \%$, and serological tests have been validated with sensitivity of $86.7 \%$ and specificity of $96.8 \% .{ }^{13}$ Validation of the noninvasive urea breath test and stool antigen test is still required. Gastrointestinal endoscopy has limited availability and is predominantly utilized on Java Island, and it is not fully covered by health insurance. ${ }^{14}$ Invasive detection of $H$. pylori infection in Indonesia is still an unfavourable choice.

In this review, we provided the current status of $H$. pylori in low risk gastric cancer country about what factor differentiating to those with high incidence of gastric cancer, including prevalence and its risk factors, $H$. pylori associated diseases, virulence factors and the antibiotic resistance, with some proposed recommendations.

\section{PREVALENCE AND RISK FACTORS OF H. pylori INFECTION}

In general, the prevalence of $H$. pylori infection is more than $90 \%$ in peptic ulcer patients who are not using nonsteroidal anti-inflammatory drugs ${ }^{15}$ and $20 \%$ to $40 \%$ among patients with functional dyspepsia according to various diagnostic methods. ${ }^{16}$ In six studies of dyspeptic patients in Indonesia, the prevalence of $H$. pylori infection varied from $5.7 \%$ to $68 \%{ }^{17-19}$ The highest prevalence was found in Jakarta using the rapid urease test, culture and histology. ${ }^{20}$ The results of the urea breath test varied but

Table 1. Summary of Helicobacter pylori Infection Prevalence, Virulence Factor and Antibiotic Resistance in Indonesia

\begin{tabular}{|c|c|c|c|c|c|c|c|c|c|}
\hline Characteristic & Bali & Java & Kalimantan & Papua & Sumatera & Sulawesi & Timor & Total & Reference \\
\hline H. pylori prevalence & $7(11.5)$ & $17(4.0)$ & $6(6.7)$ & $9(42.9)$ & 26 (19.8) & $13(14.9)$ & $14(40.0)$ & $88(10.4)$ & 23 \\
\hline Subjects (number) & 61 & 424 & 90 & 21 & 131 & 87 & 35 & 849 & \\
\hline Virulence factor & & & & & & & & & 23 \\
\hline cagA positive & $6(100)$ & $11(78.6)$ & $5(100)$ & $7(100)$ & 18 (100) & $13(100)$ & 13 (92.9) & 73 (94.8) & \\
\hline \multicolumn{10}{|l|}{ cagA type } \\
\hline East Asian-type & $3(50.0)$ & $10(71.4)$ & $2(40.0)$ & $1(14.3)$ & 18 (100) & $9(69.2)$ & $6(42.9)$ & $49(67.1)$ & \\
\hline Western-type & $3(50.0)$ & $1(7.1)$ & $3(60.0)$ & 0 & 0 & $4(30.8)$ & $7(50.0)$ & $18(24.7)$ & \\
\hline ABB-type & 0 & 0 & 0 & $6(85.7)$ & 0 & 0 & 0 & 6 (8.2) & \\
\hline $\operatorname{vac} A \mathrm{~s} 1 / \mathrm{m} 1$ & $6(100.0)$ & $7(50.0)$ & $5(100)$ & $7(100)$ & $9(50.0)$ & $6(46.2)$ & $12(85.7)$ & $52(67.5)$ & \\
\hline oipA "on" & $6(100.0)$ & $12(85.7)$ & $4(80.0)$ & $6(85.7)$ & $18(100)$ & 12 (92.3) & $14(100)$ & 72 (93.5) & \\
\hline dupA negative & $6(100.0)$ & $11(78.6)$ & $3(60.0)$ & $7(100)$ & $17(94.4)$ & $13(100)$ & $8(57.1)$ & $65(84.4)$ & \\
\hline Strain (number) & 6 & 14 & 5 & 7 & 18 & 13 & 14 & 77 & \\
\hline Antibiotic resistant rate & & & & & & & & & 23 \\
\hline Clarothromycin & $1(16.7)$ & $3(21.4)$ & 0 & $1(14.3)$ & $1(7.7)$ & $1(5.6)$ & 0 & $7(9.1)$ & \\
\hline Amoxicillin & 0 & 0 & 0 & $1(14.3)$ & $1(7.7)$ & $1(5.6)$ & $1(7.1)$ & $4(5.2)$ & \\
\hline Metronidazole & 2 (33.3) & $7(50.0)$ & $1(20.0)$ & $3(42.9)$ & $4(30.8)$ & $16(88.9)$ & $3(21.4)$ & $36(46.7)$ & \\
\hline Levofloxacin & $1(16.6)$ & $7(50.0)$ & $1(20.0)$ & $2(28.6)$ & $2(15.4)$ & $8(44.4)$ & $3(21.4)$ & 24 (31.2) & \\
\hline Tetracycline & 0 & $2(14.3)$ & 0 & 0 & 0 & 0 & 0 & $2(2.6)$ & \\
\hline Strain (number) & 6 & 14 & 5 & 7 & 18 & 13 & 14 & 77 & \\
\hline Furazolidone & 0 & 0 & 0 & 0 & 0 & 0 & 0 & 0 & 24 \\
\hline Sitafloxacin & 0 & 0 & 0 & 0 & 0 & 0 & 0 & 0 & \\
\hline Garenoxacin & 0 & $2(15.4)$ & 0 & 0 & 0 & $3(16.7)$ & 0 & $5(6.5)$ & \\
\hline Rifaximin & $3(50.0)$ & $4(30.7)$ & $3(60.0)$ & 2 (28.5) & $6(46.1)$ & $3(16.7)$ & $6(42.8)$ & 27 (35.5) & \\
\hline Rifabutin & 0 & 0 & 0 & 0 & 0 & 0 & 0 & 0 & \\
\hline Strain (number) & 6 & 13 & 5 & 7 & 18 & 13 & 14 & 76 & \\
\hline
\end{tabular}

Data are presented as number (\%). 
usually found a low prevalence of $H$. pylori infection, from $0 \%$ to $11.2 \%{ }^{18,19,21}$ We found several reasons for these inconsistent results, including the accuracy of each $\mathrm{H}$. pylori test, differences between location of the biopsy, differences between pathologists and variation in the evaluation criteria. $^{22}$ Furthermore, most of these studies were conducted in the region where Javanese was the predominant ethnicity.

To clarify the reasons for these inconsistent results, our study in Surabaya, Java Island applied five different methods to detect $H$. pylori infection: culture, histology, immunohistochemistry, rapid urease test and urine antibody test and found that the prevalence of $H$. pylori infection was low (11.5\%) based on at least one positive result among those five tests. ${ }^{22}$ We then expanded the study to include 849 patients from the five largest islands representing at least 13 ethnic groups. The prevalence was still considerably low with only $10.4 \%$ (Table 1 ). ${ }^{23,24}$ In contrast with neighboring countries such as Thailand and the Philippines, with prevalence rates of $76.1 \%$ and $60 \%$, respectively, ${ }^{25,26}$ we found a low prevalence of $22.1 \%{ }^{27}$ Another survey in North Sulawesi province using urine tests in 251 adult patients of predominantly Minahasanese and Mongondownese ethnicity detected $H$. pylori in only $14.3 \%$ of subjects. A prevalence of $H$. pylori infection of only $3.8 \%$ was reported in a population of children in North Sulawesi, Indonesia. ${ }^{28}$

The prevalence of $H$. pylori infection in Indonesia was generally low, in concordant with Malaysia and Singapore but in contrast with several other areas in Southeast Asia such as Vietnam or Thailand. Thus, epidemiology of $H$. pylori infection can be varied among regions. ${ }^{29}$ This low prevalence of $H$. pylori may be correlated with the low gastric cancer incidence in Indonesia. East Asian country such as Korea and Japan reported a high ASR of gastric cancer and also showed a high $H$. pylori infection prevalence; $54.0 \%$ and $51.4 \%$ respectively (Table 2), ${ }^{4,5,8,23,27,30-37}$ even in some cases there were some probability to be infected with non-H. pylori organism. ${ }^{38}$ These phenomena may support the role of $H$. pylori in the gastric cancer pathogenesis.

A collaborative study among South Asian countries reported that host genetic susceptibility, genetic diversity of $H$. pylori and environmental factors were associated with $H$. pylori infection. ${ }^{39-41}$ Several habits may significantly increase $H$. pylori prevalence, such as eating food with fingers, rarely washing hands before eating, eating cucumbers more than once a week and drinking alcohol. ${ }^{42}$ Other risk factors, such as salary, source of water, type of latrine, history of medicine intake, religion, and smoking were associated with the prevalence of $H$. pylori infection in Indonesia. ${ }^{27}$ The most important factors related to the risk of $H$. pylori infection are differences in ethnicity and geographical areas in Indonesia. For example, we showed that, after adjustment for age and sex, the risk of $H$. pylori infection in people of Papuan, Batak, and Buginese ethnicity was 30.57-, 28.39- and 23.23-fold, respectively, higher than that in Javanese. Moreover, the prevalence of $H$. pylori infection among young people of these ethnic groups was higher than that among Javanese of the same age group. ${ }^{27}$

\section{H. pylori-ASSOCIATED DISEASE}

\section{Dyspepsia and gastritis}

Dyspepsia is a major associated disease of $H$. pylori infection. Dyspepsia is estimated to be present in $25 \%$ of Indonesian population. ${ }^{43}$ Several factors cause dyspepsia, including $H$. pylori infection, stress, metabolic disease, medication and functional dyspepsia. Dyspepsia has been

Table 2. Comparison of Helicobacter pylori Profiles of Indonesia and Japan

\begin{tabular}{|c|c|c|c|c|}
\hline Variable & Indonesia, \% & Japan, \% & Korea, \% & References \\
\hline Prevalences of $H$. pylori infection & 10.1 & 51.7 & 54.0 & 4,8 \\
\hline \multicolumn{5}{|l|}{ Disease in $H$. pylori positive } \\
\hline Duodenal ulcer & 2.3 & 22.7 & 18.4 & $27,30,31$ \\
\hline Gastric ulcer & 11.4 & 16.4 & 23.9 & $27,30,31$ \\
\hline Gastric cancer & 0.9 & 13.1 & 13.4 & 5 \\
\hline \multicolumn{5}{|l|}{ Virulence type } \\
\hline $\operatorname{cag} A$ positive & 97.7 & 100 & 94.1 & $27,31,32$ \\
\hline East Asian type & 60.5 & 97.7 & 96.2 & $27,32,33$ \\
\hline ABB type & 18.6 & - & - & 27 \\
\hline $\operatorname{vac} A \mathrm{~s} 1 \mathrm{~m} 1$ & 70.4 & 96.5 & 77.6 & $27,32,34$ \\
\hline $\operatorname{dup} A$ & 6.8 & 21.0 & 48.0 & 27,35 \\
\hline \multicolumn{5}{|l|}{ Antibiotic resistance } \\
\hline Amoxicillin & 5.2 & 13.0 & 9.5 & $23,34,36$ \\
\hline Clarithromycin & 9.1 & 48.0 & 17.8 & $23,34,36$ \\
\hline Metronidazole & 46.7 & 49.0 & 29.5 & $23,34,36$ \\
\hline Levofloxacin & 31.2 & 15.0 & 37.0 & $23,34,37$ \\
\hline
\end{tabular}


shown to decrease the quality of life in Indonesia. Additionally, several factors, such as female sex, older age and more severe dyspepsia symptoms, can worsen the quality of life of individuals with dyspepsia. ${ }^{44}$ Most dyspepsia cases are due to inflammation of the gastric mucosa, which can be observed by endoscopic or histological examination. Observation of 247 dyspeptic individuals in the three cities found that a lower pepsinogen I/II ratio was correlated with a higher inflammation score in the antrum and corpus. ${ }^{7}$ In addition, an inverse correlation was observed between pepsinogen levels and $H$. pylori infection status. ${ }^{7}$ An Indonesian study of 1,139 endoscopic patients found that H. pylori infection was the main factor in acute and chronic gastric mucosal inflammation, regardless of ethnicity and geographical location, increasing the odds of acute and chronic gastric mucosal inflammation by 185 and 300, respectively. ${ }^{8}$ These findings suggest an important role of $H$. pylori infection in the progression of gastric inflammation, even in areas with a low prevalence of $H$. pylori infection.

\section{Peptic ulcer}

Although dyspepsia is one of the most common complaints of patients who visit healthcare providers, the prevalence of peptic ulcer in Indonesia is low. ${ }^{14}$ Our nationwide survey of 17 cities in Indonesia found that 77 of 1,139 dyspeptic patients who underwent endoscopic examination had a sign of ulceration. This finding indicates a low prevalence of peptic ulcer in Indonesia compared with that in neighboring countries, such as $50.9 \%$ in Malaysia, ${ }^{45}$ $47.6 \%$ in Thailand, ${ }^{46}$ and $5.6 \%$ to $14.7 \%$ in Vietnam. ${ }^{47,48}$

Peptic ulcer disease (PUD) consists of the duodenal ulcer and gastric cancer. The development of duodenal ulcer and gastric cancer is associated with different cascade mechanisms, ${ }^{49}$ suggesting that the mechanism of the diseases may be more complex than we previously expected. Gastric ulcer has the higher risk to become gastric cancer while the duodenal ulcer was less likely. ${ }^{50}$ The first cohort study in Japan by Uemura et al. ${ }^{51}$ mentioned that the gastric ulcer was likely found in the patients with the $H$. pylori positive. In that study, $23.8 \%$ of the $H$. pylori positive patients had gastric ulcer and $16.4 \%$ in the other study in Japanese population. ${ }^{30,51}$ While in Korea, 23.9\% of $\mathrm{H}$. pylori infected patient has gastric ulcer. Concordant with the result in Indonesia, $11.3 \%$ of the $H$. pylori positive patients were also had gastric ulcer (Table 2). Even though the total number of gastric ulcer patients in Indonesia may be lower than Japan due to the national low infection prevalence, we still need to be cautious on treating the patients in some specific ethnics that showed higher infection prevalence.

The development of ulceration in the stomach and duodenum involves a complex inflammatory pathway that induces degeneration of the gastric mucosa ${ }^{52,53} \mathrm{~A}$ study showed that $H$. pylori has a virulence factor that has a strong association with duodenal ulcer but a protective effect against gastric cancer, known as the duodenal ulcer promoting (dupA) gene. ${ }^{35}$ In fact, there was no intact longtype $\operatorname{dup} A$, the real virulence marker of $\operatorname{dup} A$ for severe outcomes, ${ }^{54}$ in the Indonesian strain. In our study, shorttype $\operatorname{dup} A$ was predominant, and all peptic ulcer patients were $\operatorname{dup} A$-negative. ${ }^{55}$ On contrary, the rate of $\operatorname{dup} A$ positive in the area with higher gastric cancer risk such as Korea and Japan, showed higher prevalence; $48 \%$ and $21 \%$ respectively (Table 2). Further research on the development of ulceration in the gastric and duodenal mucosa needs to be performed, especially in areas of low $H$. pylori infection, such as Indonesia.

\section{Gastric cancer}

H. pylori infection can cause inflammatory symptoms of gastritis, but only $10 \%$ to $20 \%$ of cases develop into gastric ulcers, and only $1 \%$ to $2 \%$ are at risk for developing non-cardiac gastric cancer. ${ }^{51}$ Gastric ulcer, duodenal ulcer, mucosa-associated lymphoid tissue lymphoma and gastric adenocarcinoma are diseases of the gastrointestinal tract known to be caused by $H$. pylori infection. ${ }^{56,57}$ A metaanalysis reported that $H$. pylori infection was strongly associated with gastric cancer, with an odds ratio (OR) of 3.00 and a $95 \%$ confidence interval of 2.42 to $3.72 .{ }^{58}$ Antral predominant gastritis and corpus predominant gastritis can lead to the two different pathogenesis of disease. In antralpredominant gastritis, there is an increase in gastric acid production, resulting in a high flow of acid to the duodenum and metaplasia of the duodenum. The location of this tissue change is called the gastric mucosa island, which facilitates other $H$. pylori infections. H. pylori infection and high acid exposure are destructive, leading to duodenal ulcers. In predominantly corpus infections, there is a disruption of acid production by parietal cells, the majority of which are in the corpus. As a result, stomach acid production decreases and the stomach become hypochlorhydric. Reduced acidity causes an increase in H. pylori infection, both in the corpus and in the antrum, increasing the risk of developing gastric ulcers and gastric cancer. ${ }^{59}$

$H$. pylori infection is associated with severe atrophic gastritis. Atrophic gastritis increases gastric $\mathrm{pH}$ and induces bacterial overgrowth that alters the local metabolism. In atrophic gastritis, gastric gland structure is replaced by connective tissue. This is called non-metaplastic atrophy, whereas replacement by an inappropriate glandular structure is called metaplastic atrophy. ${ }^{60}$ Gastric cancer is initially marked by severe atrophic gastritis, infiltration of lymphocytes/plasma cells and neutrophils in the corpus 
and intestinal metaplasia in the antrum and/or corpus. ${ }^{8}$ Corpus-predominant gastritis is common in countries with a high risk of gastric cancer, whereas antrum-predominant gastritis is more common in low-risk countries. ${ }^{24,61-63} \mathrm{Mon}$ itoring atrophic gastritis could be a method of determining the incidence of gastric cancer.

Studies of gastric mucosal status and gastric cancer risk analysis in Indonesian populations showed that antrumpredominant gastritis is predominant in patients with chronic gastritis. ${ }^{8}$ Corpus-predominant gastritis is associated with a high incidence of gastric cancer in China (ASR of 22.73/100,000). Antrum-predominant gastritis can develop into duodenal ulcer, but it is less likely to develop into gastric cancer. This supports the finding that Indonesia is a country with a low risk of gastric cancer. The prevalence of gastric ulcer is lower in Indonesia than in other Asian countries, such as India and Malaysia. ${ }^{27}$

A study in Indonesia ${ }^{8}$ showed that almost half of individuals with dyspeptic symptoms had histological abnormalities, including acute, chronic with atrophic gastritis, as well as intestinal metaplasia. The association between the prevalence of chronic active gastritis and the prevalence of atrophic gastritis supports the consensus that chronic active gastritis can progress to atrophic gastritis, which can further develop into cancer. ${ }^{8}$ In cases in which atrophic gastritis is absent, gastric cancer can develop from the increased activity of inflammation related to $H$. pylori infection. ${ }^{64}$ Some changes in biological functions, including increased oxidative stress along with genetic and epigenetic alterations, are capable of causing $H$. pylori-induced gastric cancer. The pathway involves degradation of the proinflammatory matrix and angiogenic pathway along with the involvement of peptidyl-prolyl cis. H. pylori trans-isomerase (HP0175), which affects the gastric Th17 response and also provides a link between $H$. pylori infection and gastric cancer. ${ }^{65,66}$ In addition, our multivariate regression analysis showed that Timor ethnicity (OR, 8.531), age (OR, 1.107), and $H$. pylori infection (OR, 22.643) are independent risk factors for atrophic gastritis. Hence, people of Timor ethnicity had the highest gastric cancer risk score. ${ }^{8}$ These data show that even though Indonesia is regarded as a country with a low risk of gastric cancer, severe gastric mucosal conditions were observed in several ethnic groups. ${ }^{7}$ This finding suggests that policymakers in Indonesia should pay attention to ethnic groups with a high risk of gastric cancer, especially for gastric cancer screening and eradication of $H$. pylori.

\section{VIRULENCE OF INDONESIAN H. pylori}

H. pylori is regarded as the most diverse and successfully colonizing pathogenic bacterium worldwide. ${ }^{67}$ These attributes are due to a high genetic diversity in its genome, which is a result of evolutionary pressures that produce genetic adaptations during human gastric colonization. ${ }^{68}$ Horizontal gene transfer, mutation, migration and genetic deviation are mechanisms associated with bacterial genetic diversity. The definition of a virulence factor refers to bacterial genes that may be responsible for inducing and developing a disease with a spectrum of severity. ${ }^{50}$ There are several well-known virulence factors of $H$. pylori, such as vacuolating cytotoxin $\mathrm{A}(\operatorname{vac} A)$, cytotoxin-associated gene A protein $(\operatorname{cag} A)$ and outer inflammatory protein A (oipA). Adherence factors, such as blood group antigen-binding adhesin $(b a b A)$ and sialic acid-binding adhesin $(s a b A)$, are also regarded as $H$. pylori virulence factors. The presence of intact Cag pathogenicity island (cag PAI) distinguishes the most virulent $H$. pylori strain, which is associated with gastric inflammation and cancer. ${ }^{69}$ We discuss here the $H$. pylori virulence factors identified in Indonesia.

\section{Cag pathogenicity island}

In 1996, a huge protein complex was discovered that encoded a secretion system that was later confirmed as a type IV secretion system (T4SS). ${ }^{69}$ This T4SS is a $40 \mathrm{kB}$ DNA consisting of a complete virB-like protein complex that forms a syringe-like pilus structure on the surface of H. pylori and has a main function of translocation of an oncogenic protein, $\mathrm{CagA} .^{70}$ Among the Cag PAI genes, the most extensively studied is cagA. The cag $A$ gene is located in the 3' terminal of the Cag PAI. It is believed to be the main cause of the inflammation of gastric epithelial cells after infection by $H$. pylori. $H$. pylori can be differentiated into $H$. pylori that produces CagA (CagA-positive) or that does not produce CagA (CagA-negative). The cagA gene has the highest diversity among Cag PAI genes. ${ }^{71}$ This high diversity is due to the Glu-Pro-Ile-Tyr-Ala (EPIYA) amino acid motif and its surrounding amino acids, which are known as the EPIYA segment. The EPIYA-A and EPIYA-B segments are called the first repetitions, and the EPIYA-C and EPIYA-D segments are called the second repetitions. Based on the different amino acid motifs of the second repetitions, CagA can be distinguished as the Westerntype, which is determined as $\mathrm{CagA} \mathrm{ABC}$ or $\mathrm{ABCC}$, and the East Asian-type, which is determined as CagA ABD. The difference in these amino acid motifs affects the binding affinity of CagA to the Src homology-2 domain-containing phosphatase 2 (SHP2). The East Asian-type CagA with the EPIYA-D motif had a 100-fold greater binding affinity than 
the Western-type CagA with the EPIYA-C motif. ${ }^{50}$ Stronger binding to SHP2 increases cellular Ras-extracellular receptor kinase activation, which has the clinical consequence of increasing the risks of peptic ulcer and/or gastric cancer. ${ }^{72}$

In Indonesia, East Asian-type CagA is predominant, similar to neighboring countries such as Malaysia and Vietnam, with rates of $56 \%$ and $96 \%$, respectively. However, in Cambodia and Thailand, Western-type CagA is predominant, with rates of $59 \%$ and $54 \%$, respectively. Studies of $H$. pylori strains in the five largest islands in Indonesia found that $60.5 \%$ were East Asian-type CagA, $20.9 \%$ were Western-type CagA and $18.6 \%$ were ABB-type CagA. Interestingly, Indonesia had other interesting types of CagA that were isolated from $H$. pylori strains Jayapura had an ABB-type CagA, which is very rare and has only been found outside of Indonesia in strains isolated from Aboriginals in Australia. ${ }^{55,73}$ When the result from Indonesia was compared with the result from the high gastric cancer incidence such as Japan, this lower proportion of East Asian CagA may explain why the gastric cancer risk was generally low in Indonesia. It is reported that East Asian CagA is predominant in Japan and South Korea with $97.7 \%$ and $96.2 \%$, respectively. ${ }^{32,33}$ Therefore, the detection of East Asian CagA may become a biomarker for developing gastric cancer. ${ }^{74}$ However, in Mongolia which was reported as the second highest ASR of gastric cancer (ASR of 33.1/100,000 population), those individuals mostly infected by non-East Asia H. pylori. ${ }^{75,76}$ These data suggest, the development of gastric cancer could not be explained by the CagA type alone.

In addition to the CagA EPIYA segment differences, there is another important determinant factor known as the pre-EPIYA region. This region, which is located about 300 base pairs (bp) upstream of the first EPIYA motif, has also been investigated as a virulence factor. ${ }^{77}$ Geographical area analysis showed specific pre-EPIYA types. The preEPIYA region can contribute to the incidence of gastric cancer. Most strains from East Asia have 39 bp deletiontype pre-EPIYA, whereas in Western countries most strains have no deletion of pre-EPIYA. ${ }^{55}$ This contrasts with the findings in Indonesia, where most of the East Asian-type cagA strains are not the 39-bp deletion-type pre-EPIYA that are commonly found but 6 bp deletion-type preEPIYA (48.8\%), followed by 18 bp deletion (25.6\%), no deletion (18.6\%) and 39 bp deletion (7\%). ${ }^{55}$ The finding is also different from that in other Asian countries in Vietnam, which is dominated by strains with 18 bp deletiontype pre-EPIYA (75\%). ${ }^{55}$ In fact, the risk of gastric cancer is higher in Vietnam than in Indonesia. Therefore, a new genetic genomic diversity marker for $H$. pylori strains in Indonesia could use a 6 bp deletion-type pre-EPIYA.

\section{Integrating conjugative elements of $\boldsymbol{H}$. pylori}

In addition to the Cag PAI, there is another interesting PAI that is also the result of horizontal gene transfer, known as Integrating Conjugative Elements of $H$. pylori (ICEHptfs) (Fig. 1). Because it carries T4SS, it is reported that ICEHptfs $4 \mathrm{~b}$ have higher inflammatory action than PAIs carrying incomplete T4SS or no T4SS ${ }^{78,79}$ Its activity is reported to be enhanced in acidic and adherent conditions. ${ }^{80}$

The worldwide distribution of ICEHptfs is extensive, with more than $80 \%$ of $H$. pylori carrying ICEHptfs. ${ }^{81,82}$ However, recent observations found that only about half of Indonesian $\mathrm{H}$. pylori carried ICEHptfs, consisting of ICEHptfs3-tfs4a (42.8\%) and ICEHptfs3 (16.3\%), and its variability among all Indonesian $H$. pylori was determined by the ethnic group of the infected host. Virulence analy-
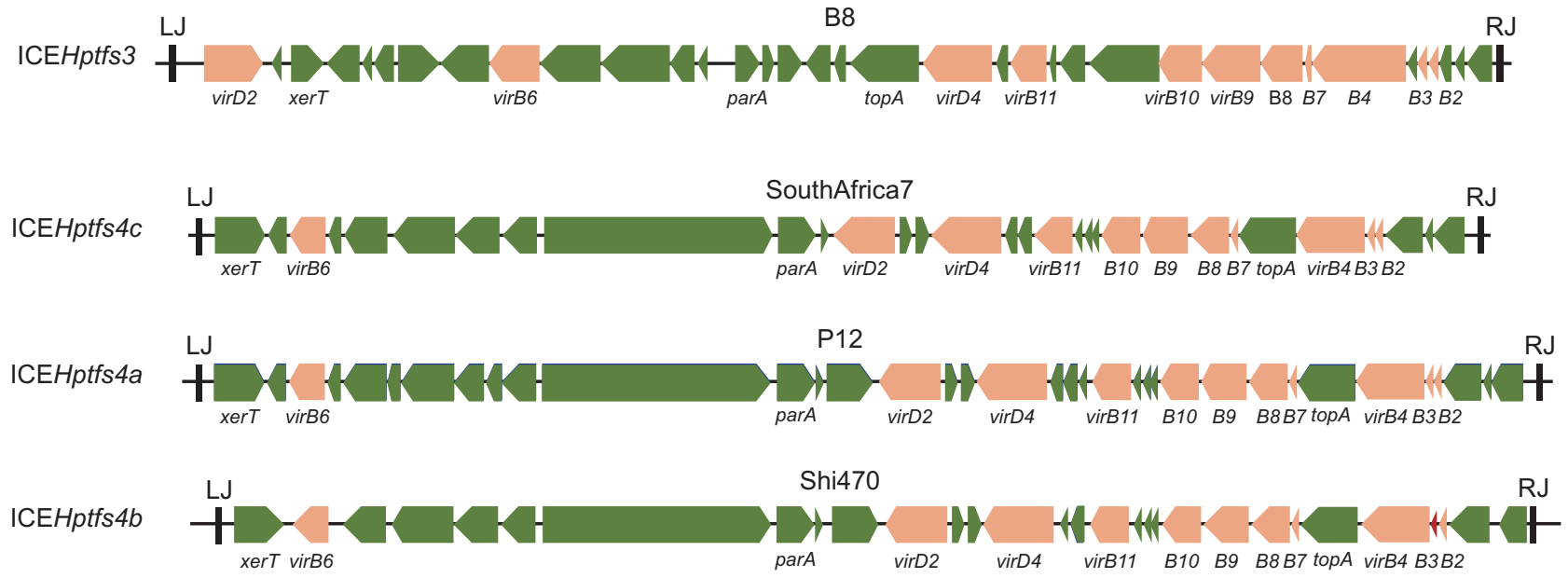

Fig. 1. Schematic figure of several Integrating Conjugative Elements of $H$. pylori (ICEHptfs) types. The ICEHptfs has two distinct varieties, ICEHptfs4 and ICEHptfs3. Its genetic variability is mainly due to the different genetic characteristics of virB8, virB9 and virD4. 
sis of ICEHptfs and cag PAI showed that inflammation was more severe in patients infected with intact cag PAIICEHptfs-positive strains than in those infected with nonintact cag PAI-ICEHptfs-negative strains. ${ }^{79}$ This finding suggests that ICEHptfs is associated with the more virulent strains of $H$. pylori.

\section{Other $\boldsymbol{H}$. pylori virulence factors}

$v a c A$ is a virulence factor that has been comprehensively studied in $H$. pylori. Its vacuolating activity varies according to the vacA sequence structure of the signal region (s1 and s2) and the middle region ( $\mathrm{m} 1$ and $\mathrm{m} 2$ ). The vacA s1 type is divided into sla, s1b, and s1c and the vacA $\mathrm{ml}$ type is divided into mla, $\mathrm{mlb}$, and $\mathrm{m} 1 \mathrm{c}^{50}{ }^{50}$ These sequence variations result in differences in secreted proteins and expression levels that are associated with disease severity. ${ }^{83}$ Studies in Latin America, West Asia, and Africa reported that the risk of peptic ulcer or gastric cancer was higher in patients infected with the $\mathrm{s} 1 \mathrm{~m} 1 \mathrm{vac} A$ type than in those infected with the $\mathrm{s} 2 \mathrm{~m} 2 \mathrm{vacA}$ type. ${ }^{11}$ The high toxicity of $\mathrm{s} 1$ $\mathrm{m} 1$ strains was supported by an in vitro study showing that s1 $\mathrm{m} 1$ strains consistently induced cell vacuolation. ${ }^{73} \mathrm{Ob}$ servations of variability in $v a c A$ in Indonesia showed that $\mathrm{s} 1 / \mathrm{m} 1$ was the predominant type, followed by $\mathrm{s} 1 / \mathrm{m} 2$ and $\mathrm{s} 2 / \mathrm{m} 2$, suggesting that the $H$. pylori circulating in Indonesia was the virulent strain. ${ }^{55}$

The outer membrane protein OipA is another virulence factor that induces interleukin 8 (IL-8) and aids the adhesion of H. pylori. Slipped-strand mispairing based on the number of CT dinucleotide repeats in the 5' region of the oipA gene regulates the functional status (on or off) of OipA ${ }^{84} H$. pylori colonization density, IL-8 levels and neutrophil infiltration were higher in the human stomach infected with an oipA "on" strain, ${ }^{85}$ even though the OipA receptor has not been identified.

The previous study reported strong associations of oip $A$ "on" status with vacA s1/m1, cagA-positive and babA2positive genotypes. ${ }^{86}$ Furthermore, patients infected with strains with oipA "on" status are at higher risk for duodenal ulcer, regardless of other virulence factors. ${ }^{87}$ Higher risks for PUD (OR, 3.97) and gastric cancer (OR, 2.43) with infection by the oip $A$ "on" strain were also reported in the previous meta-analysis. ${ }^{88}$ Thus, analysis of the presence or absence of the oipA gene without regard to functional on/ off status may be unable to predict the risk of PUD or gastric cancer. ${ }^{88}$ However, a recent study found that the oipA "on" type was observed in more than $80 \%$ of Indonesian H. pylori. ${ }^{23}$ Based on these findings, Indonesian H. pylori can be considered as virulence type 1 ; however, the prevalence of gastric cancers in Indonesia was very low. This observation showed that the pathogenesis of gastric cancer, especially in Indonesia, is more complex than we predicted previously.

\section{ANTIBIOTIC RESISTANCE}

Because of the ability of $H$. pylori to remain in an asymptomatic host, $H$. pylori infection is a serious infectious disease. H. pylori can also cause gastritis and other complications, such as gastric ulcer and gastric cancer. Thus, according to the Kyoto global consensus conference on $H$. pylori gastritis in 2014, $H$. pylori infection needs to be eradicated. ${ }^{89}$ Recent guidelines have proposed indications to start the treatment and regimens used for treatment in the Asia-Pacific and Association of Southeast Asian Nations (ASEAN) regions. ${ }^{90,91}$ With regard to regimens used for $H$. pylori infection, standard triple therapy with proton pump inhibitors, clarithromycin and amoxicillin is the most popular in areas with clarithromycin resistance rates lower than 15\%. There are several regimens that available for first-line therapy and salvage therapy according to Asia-Pacific consensus. ${ }^{92}$ However, besides all of the possible combinations of drugs, the best option is to choose the best antimicrobial agents for each patient, according to susceptibility tests. ${ }^{93}$

In the ASEAN region, more attention should be paid to $H$. pylori resistance to metronidazole and clarithromycin. Metronidazole-resistant $H$. pylori remains a major antibiotic-resistant pathogen in the region. The prevalence of metronidazole resistance varies among ASEAN countries. Cambodia has the highest prevalence (73\%), followed by Vietnam (70\%), Singapore (48\%), Myanmar (36.5\%), Thailand (36\%), and the Philippines (30\%). Clarithromycin resistance is now at a high level, and the use of clarithromycin-based triple therapy is no longer recommended, ${ }^{94}$ although Southeast Asia is the region in Asia with the lowest clarithromycin resistance rates among Asian countries. ${ }^{95}$ The prevalence of clarithromycin resistance varies among ASEAN countries, being high in Cambodia (43\%), Vietnam (30\%), moderate to high in Singapore (17\%) and low in Malaysia (6.8\%), the Philippines (2\%), and Myanmar $(0 \%) .{ }^{94}$ In comparison with the East Asian counties, such as Japan, Clarithromycin resistance in Indonesia was also considered to be low. However, metronidazole resistance was almost similar. ${ }^{36}$

Studies of the antibiotic susceptibility of $H$. pylori in Indonesia showed that Indonesian strains had high prevalence of metronidazole and levofloxacin resistance and low prevalence of clarithromycin, amoxicillin and tetracycline resistance. ${ }^{23}$ A study from Indonesia in 2016 of the antibiotic susceptibility of $H$. pylori in Indonesia found that 
strains from Java and Bali Islands had clarithromycin resistance rates greater than $15 \%$ (21.4\% and $16.7 \%$, respectively), which is the recommended resistance limit for eradication therapy without conducting susceptibility tests. Java Island had a high rate of tetracycline resistance of $14.3 \%$. Java and Sumatra Islands had the highest rates of levofloxacin resistance, with $50 \%$ and $44.4 \%$, respectively. The highest rate of metronidazole resistance occurred in Sumatra $(88.9 \%)$, followed by Java (50.0\%), Papua (42.9\%), Bali (33.3\%), Sulawesi (30.8\%), Timor (21.4\%), and Kalimantan (20.0\%). All these rates are taken from study reports based on geographical location in Indonesia. Research on the prevalence of antibiotic resistance based on ethnic groups showed that strains from Ambonese (50.0\%), Chinese (20.0\%), and Balinese (16.6\%) had high prevalence of clarithromycin resistance that exceeded the recommendations of the Maastricht Guidelines (>15\% to 20\%). ${ }^{90}$ Dayak was the only ethnic group in which $H$. pylori was sensitive to all antibiotics (clarithromycin, amoxicillin, metronidazole, levofloxacin and tetracycline). In areas with a high prevalence of clarithromycin resistance $(>15 \%)$, standard triple therapy should not be used as first-line treatment and quadruple therapy would be a better choice. At present, H. pylori eradication with standard triple therapy was reported $<70 \%$ eradication rate which is ineffective in several countries worldwide including ASEAN countries. ${ }^{23,94}$ Therefore, H. pylori antibiotic therapy should be administered carefully in some regions of Indonesia. Furthermore, the low prevalence of amoxicillin resistance in Indonesia suggests that the use of amoxicillin as a first-line therapy needs to be considered.

The mechanism of antibiotic resistance by $H$. pylori may guide the doctor to achieve the treatment target and initiate the development of new drugs. Clarithromycin is commonly used in first-line regimens for $H$. pylori treatment with bacteriostatic mechanisms. The bacteria become resistant due to a decrease in the affinity of the ribosomes for the drug, by mutations in various points in domain $\mathrm{V}$ of the ribosomal RNA (rRNA) 23R (Table 3). ${ }^{92,95} \mathrm{We}$ found an interesting point mutation, A2143G, in Indonesian clarithromycin-resistant strains. When we performed next-generation sequencing, a novel mutated sequence in hp1314 (rpl22), including 19 bp deletions at position 535, was found. ${ }^{23}$

There are at least four mechanisms of resistance to metronidazole that summarized in Table $3 .{ }^{23,92,95,96}$ Levofloxacin is a broad-spectrum fluoroquinolone drug that eradicates $H$. pylori. ${ }^{92,95}$ Indonesian strains have amino acid substitutions at Asp-91 and Asn-87 that are associated with the highest minimum inhibitory concentration values observed. In addition, amino acid substitutions at Arg-484 and Ser-479 in the gyrB subunit were observed.

The guidelines for managing $H$. pylori infection are still being developed based on variations in geographical area. ${ }^{97}$ According to the Bangkok consensus report recommendation, each country should develop its own appropriate first-line regimen based on its antibiotic resistance pattern. The second-line regimen should consist of a drug that has never been used in the country and to which $H$. pylori is susceptible in most of the population. ${ }^{90}$ Vonoprazan has recently been approved in Japan for eradication of $H$. pylori strains that are resistant to clarithromycin with a mechanism of blocking potassium competitive acid P-CAB. ${ }^{98}$ It might be another alternative due to the high prevalence of clarithromycin resistance in some areas in Indonesia. Other alternative regimens, such as furazolidone, rifabutin and sitafloxacin, have been suggested in Indonesia where there is an increase in levofloxacin resistance in the absence of bismuth treatment. ${ }^{24}$ Antibiotic susceptibility tests, such as the E-Test or molecular methods, can be used before starting appropriate treatment in cases of more than two treatment failures. ${ }^{90,99}$ However, the use of antibiotic susceptibil-

Table 3. Mechanisms of Antibiotic Action and Resistance for Clarithromycin, Metronidazole and Levofloxacin ${ }^{23,92}$

\begin{tabular}{|c|c|c|}
\hline Antibiotics & Mechanism of drug action & Mechanism of resistant \\
\hline Clarithromycin & $\begin{array}{l}\text { Binds to } 23 \mathrm{~S} \text { rRNA (part of } 50 \mathrm{~S} \text { subunit } \\
\text { of the bacterial ribosome) so it can } \\
\text { inhibit the protein translation }\end{array}$ & $\begin{array}{l}\text { Mutation in the } V \text { segmen of } 23 \text { s rRNA gene especially in locus } 2142 \mathrm{G}, \mathrm{A} 2142 \mathrm{C} \text { and } \\
\quad \mathrm{A} 2143 \mathrm{G} \text { and the most rarely found are } 2144 \mathrm{~T}, \mathrm{~T} 2717 \mathrm{C} \text { and C2694A. } \\
\text { Alteration in translation initiation of IF2. } \\
\text { L22 ribosomal proteins gene mutation. } \\
\text { Increasing expression of efflux pump. }\end{array}$ \\
\hline Metronidazole & Degrade bacterial DNA & $\begin{array}{l}\text { Reduction in the uptake of the antibiotic and/or an increase in the efflux of the } \\
\text { antibiotic through the bacterial wall. } \\
\text { Mutation in } f d x B \text { gene encoding ferredoxin-like protein. } \\
\text { Mutations of the } r d x A \text { and frxA genes. }\end{array}$ \\
\hline Levofloxacin & $\begin{array}{l}\text { Inhibit DNA gyrase so that DNA synthe- } \\
\text { sis is disrupted }\end{array}$ & $\begin{array}{l}\text { Mutations in the gyrA DNA, subunits A or B, which caused the D91 position to be } \\
\text { changed to G, N, A or Y, N87K and A88V. } \\
\text { Mutation in the gyrB gene such as D481E or R484K. }\end{array}$ \\
\hline
\end{tabular}

rRNA, ribosomal RNA. 
ity tests is difficult in Indonesia due to the lack of facilities and high costs. Estimating the prevalence of antibiotic resistance in local situations from local surveillance and/or local clinical experience can help provide appropriate care in eradicating $H$. pylori in each case. In addition, a detailed evaluation of the patient's previous use of antibiotics is important to reduce the resistance of $H$. pylori to antibiotics in Indonesia.

\section{OTHER MICROBIOTA THAN H. pylori}

Microbiota is a term for the micro-organisms living in a particular location. The location may be a macro-environment such as a national park or a microenvironment such as soil, seawater or even human skin or stomach. The diversity of microbiota may explain several matters, such as how environmental conditions affect what kind of bacteria can live in that particular environment, how bacteria evolve with changes in environmental conditions and how changing the environment may change the bacterial composition. ${ }^{100}$ The microbiota of the gastric environment in relation to the pathogenesis of diseases is an interesting topic to discuss. It was believed that the stomach was a somewhat sterile environment due to its high acidity and the low level of cultured bacteria from inside the stomach. However, recent advanced technology has shown that the stomach has a large and diverse bacterial community with a density ranging from 10 to 1,000 colony-forming units. ${ }^{101}$ Not only $H$. pylori, gastric microbiota may play roles in the gastric epithelial homeostasis and carcinogenesis. ${ }^{102}$

Utilizing a clone of small subunit $16 \mathrm{~S}$ rDNA, the results from 23 gastric biopsies revealed a diverse bacterial community of 128 phylotypes, with the majority of bacteria belonging to the Proteobacteria, Firmicutes, Actinobacteria, Bacteroidetes and Fusobacteria phyla. ${ }^{103}$ These data provide evidence of a great diversity of gastric microbiota due to a large degree of intersubject variability. In addition, diet and environmental change have a strong relationship with changes of the gastric microbiota. ${ }^{104}$ However, even though the microbiota can be changed rapidly by changing the diet, the human gastric microbiota has a consistent pattern of Actinobacteria, Bacteroidetes, Firmicutes and Proteobacteria as the predominant phyla and Streptococcus as the predominant genus. ${ }^{104-106}$

In addition to altering its composition due to changes in dietary habits and environmental changes, changing the gastric microbiota may also affect the gastric condition. A study analyzing the gastric microbial community in different stages of the Correa cascade showed alterations of the gastric microbial composition. Along the Correa cascade, the microbial diversity and abundance of $H$. pylori were lower in chronic gastritis patients than in gastric cancer patients. ${ }^{107}$ There was an overrepresentation of bacterial genera that included commensal bacteria from the intestine and an increase in nitrosating potential, suggesting a role of microbiota and $H$. pylori in carcinogenesis due to the genotoxic capability. Another comparison study of the microbiota in gastritis and gastric cancer showed a significant microbial dysbiosis in individuals with intestinal metaplasia and gastric cancer, with significant enrichment of 21 and depletion of 10 bacterial taxa in gastric cancer compared with gastritis. ${ }^{108}$ In addition, five bacterial species (Peptostreptococcus stomatis, Streptococcus anginosus, Parvimonas micra, Slackia exigua, and Dialister pneumosintes) were enriched in patients with gastric cancer. ${ }^{109}$ In $H$. pylori-infected patients, the proportion of Bacteroidetes decreased while the proportions of Firmicutes and Proteobacteria increased compared with $H$. pylori-negative patients. ${ }^{110}$ The previous metagenomic analysis showed that T4SS genes were frequently observed in patients with intestinal metaplasia. This study not only analyzed the $16 \mathrm{~S}$ rRNA sequence from gastric biopsies but also sequenced the whole genome of the microbiome. It was concluded that abundant T4SS might induce more severe gastritis and carcinogenesis. ${ }^{111}$ These data suggest that gastroduodenal diseases may have a strong association with other bacteria in addition to $H$. pylori. This hypothesis also led us to the intriguing phenomenon in Indonesia of a low prevalence of $H$. pylori but a very high prevalence of dyspepsia. Our preliminary analysis of the gastric microbiota of $H$. pylorinegative patients with gastric inflammation produced several candidate bacteria that were associated with gastritis superficialis and also with precancerous lesions, including atrophic gastritis and intestinal metaplasia (unpublished data). Discussion of the development of gastroduodenal diseases, especially of the causative agents, should not consider only $H$. pylori as the pathogen. Alteration of the gastric commensal bacteria may also change the gastric environment and lead to disease.

\section{CONCLUSIONS}

Low gastric cancer incidence countries are mostly supported by low $H$. pylori infection, even the virulence is similar. It is necessary to support research on the latest developments in $H$. pylori infection. In contrast with high gastric cancer prevalence countries focusing on early detection and eradication, low gastric cancer countries should pay attention for screening to the several groups with high risk of gastric cancer. 


\section{CONFLICTS OF INTEREST}

No potential conflict of interest relevant to this article was reported.

\section{ORCID}

Muhammad Miftahussurur

https://orcid.org/0000-0003-1415-6033

Langgeng Agung Waskito

https://orcid.org/0000-0002-9400-1973

Kartika Afrida Fauzia

https://orcid.org/0000-0001-6901-3270

Isna Mahmudah https://orcid.org/0000-0001-7591-8789

Dalla Doohan https://orcid.org/0000-0003-3076-571X

I Ketut Adnyana https://orcid.org/0000-0001-5217-2312

Ali Khomsan https://orcid.org/0000-0001-6101-3583

Neneng Ratnasari https://orcid.org/0000-0003-1323-2233

Yudith Annisa Ayu Rezkitha

https://orcid.org/0000-0001-7600-9114

\section{REFERENCES}

1. Kang SJ, Park B, Shin CM. Helicobacter pylori eradication therapy for functional dyspepsia: a meta-analysis by region and H. pylori prevalence. J Clin Med 2019;8:1324.

2. Suzuki H, Moayyedi P. Helicobacter pylori infection in functional dyspepsia. Nat Rev Gastroenterol Hepatol 2013;10:168-174.

3. Zamani M, Ebrahimtabar F, Zamani V, et al. Systematic review with meta-analysis: the worldwide prevalence of Helicobacter pylori infection. Aliment Pharmacol Ther 2018;47:868-876.

4. Hooi JKY, Lai WY, Ng WK, et al. Global prevalence of Helicobacter pylori infection: systematic review and metaanalysis. Gastroenterology 2017;153:420-429.

5. Ferlay J, Ervik M, Lam F, et al. Global cancer observatory: cancer today. Lyon: International Agency ror Research on Cancer, 2018.

6. International Agency for Research on Cancer (IARC). Global Cancer Observatory [Internet]. Lyon: IARC [cited 2019 Jul 7]. Available from: https://gco.iarc.fr.

7. Miftahussurur M, Nusi IA, Akil F, et al. Gastric mucosal status in populations with a low prevalence of Helicobacter pylori in Indonesia. PLoS One 2017;12:e0176203.

8. Miftahussurur M, Waskito LA, Syam AF, et al. Analysis of risks of gastric cancer by gastric mucosa among Indonesian ethnic groups. PLoS One 2019;14:e0216670.

9. Gunaletchumy SP, Seevasant I, Tan MH, et al. Helicobacter pylori genetic diversity and gastro-duodenal diseases in Malaysia. Sci Rep 2014;4:7431.

10. Kang JY, Yeoh KG, Ho KY, et al. Racial differences in Helicobacter pylori seroprevalence in Singapore: correlation with differences in peptic ulcer frequency. J Gastroenterol Hepatol 1997;12:655-659.

11. Mahadeva S, Goh KL. Epidemiology of functional dyspepsia: a global perspective. World J Gastroenterol 2006;12:26612666.

12. Miftahussurur M, Yamaoka Y. Diagnostic methods of Helicobacter pylori infection for epidemiological studies: critical importance of indirect test validation. Biomed Res Int 2016;2016:4819423.

13. Syam AF, Miftahussurur M, Uwan WB, Simanjuntak D, Uchida T, Yamaoka Y. Validation of urine test for detection of Helicobacter pylori infection in indonesian population. Biomed Res Int 2015;2015:152823.

14. Makmun D. Present status of endoscopy, therapeutic endoscopy and the endoscopy training system in Indonesia. Dig Endosc 2014;26 Suppl 2:2-9.

15. Kuipers EJ, Thijs JC, Festen HP. The prevalence of Helicobacter pylori in peptic ulcer disease. Aliment Pharmacol Ther 1995;9 Suppl 2:59-69.

16. Ford AC, Marwaha A, Sood R, Moayyedi P. Global prevalence of, and risk factors for, uninvestigated dyspepsia: a meta-analysis. Gut 2015;64:1049-1057.

17. Syam AF, Rani AA, Abdullah M, et al. Accuracy of Helicobacter pylori stool antigen for the detection of Helicobacter pylori infection in dyspeptic patients. World J Gastroenterol 2005; 11:386-388.

18. Tokudome S, Samsuria Soeripto WD, Triningsih FX, et al. Helicobacter pylori infection appears essential for stomach carcinogenesis: observations in Semarang, Indonesia. Cancer Sci 2005;96:873-875.

19. Tokudome S, Soeripto, Triningsih FX, et al. Rare Helicobacter pylori infection as a factor for the very low stomach cancer incidence in Yogyakarta, Indonesia. Cancer Lett 2005;219:57-61.

20. Abdullah M, Ohtsuka H, Rani AA, Sato T, Syam AF, Fujino MA. Helicobacter pylori infection and gastropathy: a comparison between Indonesian and Japanese patients. World J Gastroenterol 2009;15:4928-4931.

21. Zhao Y, Wang J, Tanaka T, et al. Association between HLADQ genotypes and haplotypes vs Helicobacter pylori infection in an Indonesian population. Asian Pac J Cancer Prev 2012;13:1247-1251.

22. Miftahussurur M, Shiota S, Suzuki R, et al. Identification of Helicobacter pylori infection in symptomatic patients in Surabaya, Indonesia, using five diagnostic tests. Epidemiol Infect 2015;143:986-996.

23. Miftahussurur M, Syam AF, Nusi IA, et al. Surveillance of 
Helicobacter pylori antibiotic susceptibility in Indonesia: different resistance types among regions and with novel genetic mutations. PLoS One 2016;11:e0166199.

24. Miftahussurur M, Waskito LA, Syam AF, et al. Alternative eradication regimens for Helicobacter pylori infection in Indonesian regions with high metronidazole and levofloxacin resistance. Infect Drug Resist 2019;12:345-358.

25. Sahara S, Sugimoto M, Vilaichone RK, et al. Role of Helicobacter pylori cagA EPIYA motif and vacA genotypes for the development of gastrointestinal diseases in Southeast Asian countries: a meta-analysis. BMC Infect Dis 2012;12:223.

26. Destura RV, Labio ED, Barrett LJ, et al. Laboratory diagnosis and susceptibility profile of Helicobacter pylori infection in the Philippines. Ann Clin Microbiol Antimicrob 2004;3:25.

27. Syam AF, Miftahussurur M, Makmun D, et al. Risk factors and prevalence of Helicobacter pylori in five largest islands of Indonesia: a preliminary study. PLoS One 2015;10:e0140186.

28. Miftahussurur M, Tuda J, Suzuki R, et al. Extremely low Helicobacter pylori prevalence in North Sulawesi, Indonesia and identification of a Maori-tribe type strain: a cross sectional study. Gut Pathog 2014;6:42.

29. Quach DT, Vilaichone RK, Vu KV, Yamaoka Y, Sugano K, Mahachai V. Helicobacter pylori infection and related gastrointestinal diseases in southeast asian countries: an expert opinion survey. Asian Pac J Cancer Prev 2018;19:3565-3569.

30. Yamazaki S, Yamakawa A, Okuda T, et al. Distinct diversity of vacA, cagA, and cagE genes of Helicobacter pylori associated with peptic ulcer in Japan. J Clin Microbiol 2005;43:3906-3916.

31. Park IS, Lee YC, Park HJ, et al. Helicobacter pylori infection in Korea. Yonsei Med J 2001;42:457-470.

32. Ito Y, Azuma T, Ito S, et al. Analysis and typing of the vacA gene from cagA-positive strains of Helicobacter pylori isolated in Japan. J Clin Microbiol 1997;35:1710-1714.

33. Choi KD, Kim N, Lee DH, et al. Analysis of the 3' variable region of the cagA gene of Helicobacter pylori isolated in Koreans. Dig Dis Sci 2007;52:960-966.

34. Lee JH, Ahn JY, Choi KD, et al. Nationwide antibiotic resistance mapping of Helicobacter pylori in Korea: a prospective multicenter study. Helicobacter 2019;24:e12592.

35. Lu H, Hsu PI, Graham DY, Yamaoka Y. Duodenal ulcer promoting gene of Helicobacter pylori. Gastroenterology 2005;128:833-848.

36. Kageyama C, Sato M, Sakae H, et al. Increase in antibiotic resistant Helicobacter pylori in a University Hospital in Japan. Infect Drug Resist 2019;12:597-602.

37. Miyachi H, Miki I, Aoyama N, et al. Primary levofloxacin resistance and gyrA/B mutations among Helicobacter pylori in Japan. Helicobacter 2006;11:243-249.

38. Seo TH, Lee SY, Uchida T, et al. The origin of non-H. pylori- related positive Giemsa staining in human gastric biopsy specimens: a prospective study. Dig Liver Dis 2011;43:23-27.

39. Ansari S, Kabamba ET, Shrestha PK, et al. Helicobacter pylori bab characterization in clinical isolates from Bhutan, Myanmar, Nepal and Bangladesh. PLoS One 2017;12:e0187225.

40. Khan A, Farooqui A, Raza Y, et al. Prevalence, diversity and disease association of Helicobacter pylori in dyspeptic patients from Pakistan. J Infect Dev Ctries 2013;7:220-228.

41. Aftab H, Miftahussurur M, Subsomwong P, et al. Two populations of less-virulent Helicobacter pylori genotypes in Bangladesh. PLoS One 2017;12:e0182947.

42. Goto Y, Syam AF, Darnindro N, Hapsari FC. Prevalence and risk factors for Helicobacter pylori infection among healthy inhabitants in Northern Jakarta, Indonesia. Asian Pac J Cancer Prev 2016;17:4747-4753.

43. Simadibrata M. Dyspepsia and gastroesophageal reflux disease (GERD): is there any correlation? Acta Med Indones 2009;41:222-227.

44. Hantoro IF, Syam AF, Mudjaddid E, Setiati S, Abdullah M. Factors associated with health-related quality of life in patients with functional dyspepsia. Health Qual Life Outcomes 2018;16:83

45. Kandasami P, Harjit K, Hanafiah H. Clinical and endoscopic features of peptic ulcer bleeding in Malaysia. Med J Malaysia 2004;59:617-622.

46. Kachintorn U, Luengrojanakul P, Atisook K, et al. Helicobacter pylori and peptic ulcer diseases: prevalence and association with antral gastritis in 210 patients. J Med Assoc Thai 1992;75:386-392.

47. Nguyen TL, Uchida T, Tsukamoto Y, et al. Helicobacter pylori infection and gastroduodenal diseases in Vietnam: a cross-sectional, hospital-based study. BMC Gastroenterol 2010;10:114.

48. Binh TT, Tuan VP, Dung HDQ, et al. Molecular epidemiology of Helicobacter pylori infection in a minor ethnic group of Vietnam: a multiethnic, population-based study. Int J Mol Sci 2018;19:708.

49. Correa P, Houghton J. Carcinogenesis of Helicobacter pylori. Gastroenterology 2007;133:659-672.

50. Yamaoka Y. Mechanisms of disease: Helicobacter pylori virulence factors. Nat Rev Gastroenterol Hepatol 2010;7:629641.

51. Uemura N, Okamoto S, Yamamoto S, et al. Helicobacter pylori infection and the development of gastric cancer. N Engl J Med 2001;345:784-789.

52. Narayanan M, Reddy KM, Marsicano E. Peptic ulcer disease and Helicobacter pylori infection. Mo Med 2018;115:219224.

53. Bagheri N, Razavi A, Pourgheysari B, et al. Up-regulated Th17 cell function is associated with increased peptic ulcer 
disease in Helicobacter pylori-infection. Infect Genet Evol 2018;60:117-125.

54. Takahashi A, Shiota S, Matsunari O, et al. Intact long-type dupA as a marker for gastroduodenal diseases in Okinawan subpopulation, Japan. Helicobacter 2013;18:66-72.

55. Miftahussurur M, Syam AF, Makmun D, et al. Helicobacter pylori virulence genes in the five largest islands of Indonesia. Gut Pathog 2015;7:26.

56. Chang WL, Yeh YC, Sheu BS. The impacts of H. pylori virulence factors on the development of gastroduodenal diseases. J Biomed Sci 2018;25:68.

57. Graham DY. History of Helicobacter pylori, duodenal ulcer, gastric ulcer and gastric cancer. World J Gastroenterol 2014;20:5191-5204.

58. Yoon H, Kim N. Diagnosis and management of high risk group for gastric cancer. Gut Liver 2015;9:5-17.

59. Correa P. Gastric cancer: overview. Gastroenterol Clin North Am 2013;42:211-217.

60. Rugge M, Correa P, Dixon MF, et al. Gastric mucosal atrophy: interobserver consistency using new criteria for classification and grading. Aliment Pharmacol Ther 2002;16:12491259.

61. Binh TT, Tuan VP, Dung HDQ, et al. Advanced non-cardia gastric cancer and Helicobacter pylori infection in Vietnam. Gut Pathog 2017;9:46.

62. Gantuya B, Bolor D, Oyuntsetseg K, et al. New observations regarding Helicobacter pylori and gastric cancer in Mongolia. Helicobacter 2018;23:e12491.

63. Shiota S, Murakawi K, Suzuki R, Fujioka T, Yamaoka Y. Helicobacter pylori infection in Japan. Expert Rev Gastroenterol Hepatol 2013;7:35-40.

64. Watanabe M, Kato J, Inoue I, et al. Development of gastric cancer in nonatrophic stomach with highly active inflammation identified by serum levels of pepsinogen and Helicobacter pylori antibody together with endoscopic rugal hyperplastic gastritis. Int J Cancer 2012;131:2632-2642.

65. Tan P, Yeoh KG. Genetics and molecular pathogenesis of gastric adenocarcinoma. Gastroenterology 2015;149:11531162.

66. Correa P. Does Helicobacter pylori cause gastric cancer via oxidative stress? Biol Chem 2006;387:361-364.

67. Fischer W, Windhager L, Rohrer S, et al. Strain-specific genes of Helicobacter pylori: genome evolution driven by a novel type IV secretion system and genomic island transfer. Nucleic Acids Res 2010;38:6089-6101.

68. Moodley Y. Helicobacter pylori: genetics, recombination, population structure, and human migrations. In: Backert S, Yamaoka Y, eds. Helicobacter pylori research: from bench to bedside. Tokyo: Springer Japan, 2016:3-27.

69. Censini S, Lange C, Xiang Z, et al. cag, a pathogenicity island of Helicobacter pylori, encodes type I-specific and disease- associated virulence factors. Proc Natl Acad Sci U S A 1996;93:14648-14653.

70. Backert S, Tegtmeyer N, Fischer W. Composition, structure and function of the Helicobacter pylori cag pathogenicity island encoded type IV secretion system. Future Microbiol 2015;10:955-965.

71. Olbermann P, Josenhans C, Moodley Y, et al. A global overview of the genetic and functional diversity in the Helicobacter pylori cag pathogenicity island. PLoS Genet 2010;6:e1001069.

72. Hatakeyama M. Oncogenic mechanisms of the Helicobacter pylori CagA protein. Nat Rev Cancer 2004;4:688-694.

73. Miftahussurur M, Yamaoka Y. Helicobacter pylori virulence genes and host genetic polymorphisms as risk factors for peptic ulcer disease. Expert Rev Gastroenterol Hepatol 2015;9:1535-1547.

74. Shiota S, Matsunari O, Watada M, Yamaoka Y. Serum Helicobacter pylori CagA antibody as a biomarker for gastric cancer in East-Asian countries. Future Microbiol 2010;5:1885-1893.

75. Matsuhisa T, Yamaoka Y, Uchida T, et al. Gastric mucosa in Mongolian and Japanese patients with gastric cancer and Helicobacter pylori infection. World J Gastroenterol 2015;21:8408-8417.

76. Tserentogtokh T, Gantuya B, Subsomwong P, et al. Westerntype Helicobacter pylori CagA are the most frequent type in Mongolian patients. Cancers (Basel) 2019;11:725.

77. Uchida T, Nguyen LT, Takayama A, et al. Analysis of virulence factors of Helicobacter pylori isolated from a Vietnamese population. BMC Microbiol 2009;9:175.

78. Jung SW, Sugimoto M, Shiota S, Graham DY, Yamaoka Y. The intact dupA cluster is a more reliable Helicobacter pylori virulence marker than dupA alone. Infect Immun 2012;80:381-387.

79. Waskito LA, Miftahussurur M, Lusida MI, et al. Distribution and clinical associations of integrating conjugative elements and cag pathogenicity islands of Helicobacter pylori in Indonesia. Sci Rep 2018;8:6073.

80. Silva B, Nunes A, Vale FF, et al. The expression of Helicobacter pylori tfs plasticity zone cluster is regulated by $\mathrm{pH}$ and adherence, and its composition is associated with differential gastric IL-8 secretion. Helicobacter 2017;22:e12390.

81. Delahay RM, Croxall NJ, Stephens AD. Phylogeographic diversity and mosaicism of the Helicobacter pylori tfs integrative and conjugative elements. Mob DNA 2018;9:5.

82. Fischer W, Breithaupt U, Kern B, Smith SI, Spicher C, Haas R. A comprehensive analysis of Helicobacter pylori plasticity zones reveals that they are integrating conjugative elements with intermediate integration specificity. BMC Genomics 2014;15:310.

83. Kidd M, Lastovica AJ, Atherton JC, Louw JA. Conservation 
of the cag pathogenicity island is associated with vacA alleles and gastroduodenal disease in South African Helicobacter pylori isolates. Gut 2001;49:11-17.

84. Yamaoka Y, Kwon DH, Graham DY. A M(r) 34,000 proinflammatory outer membrane protein (oipA) of Helicobacter pylori. Proc Natl Acad Sci U S A 2000;97:7533-7538.

85. Yamaoka Y, Kikuchi S, el-Zimaity HM, Gutierrez O, Osato MS, Graham DY. Importance of Helicobacter pylori oipA in clinical presentation, gastric inflammation, and mucosal interleukin 8 production. Gastroenterology 2002;123:414-424.

86. Dossumbekova A, Prinz C, Mages J, et al. Helicobacter pylori HopH (OipA) and bacterial pathogenicity: genetic and functional genomic analysis of hopH gene polymorphisms. J Infect Dis 2006;194:1346-1355.

87. Yamaoka Y, Orito E, Mizokami M, et al. Helicobacter pylori in North and South America before Columbus. FEBS Lett 2002;517:180-184

88. Liu J, He C, Chen M, Wang Z, Xing C, Yuan Y. Association of presence/absence and on/off patterns of Helicobacter pylori oipA gene with peptic ulcer disease and gastric cancer risks: a meta-analysis. BMC Infect Dis 2013;13:555.

89. Sugano K, Tack J, Kuipers EJ, et al. Kyoto global consensus report on Helicobacter pylori gastritis. Gut 2015;64:13531367.

90. Mahachai V, Vilaichone RK, Pittayanon R, et al. Helicobacter pylori management in ASEAN: the Bangkok consensus report. J Gastroenterol Hepatol 2018;33:37-56.

91. Fock KM, Katelaris P, Sugano K, et al. Second Asia-Pacific Consensus Guidelines for Helicobacter pylori infection. J Gastroenterol Hepatol 2009;24:1587-1600.

92. Alba C, Blanco A, Alarcón T. Antibiotic resistance in Helicobacter pylori. Curr Opin Infect Dis 2017;30:489-497.

93. Savoldi A, Carrara E, Graham DY, Conti M, Tacconelli E. Prevalence of antibiotic resistance in Helicobacter pylori: a systematic review and meta-analysis in world health organization regions. Gastroenterology 2018;155:1372-1382.

94. Vilaichone RK, Quach DT, Yamaoka Y, Sugano K, Mahachai V. Prevalence and pattern of antibiotic resistant strains of Helicobacter pylori infection in ASEAN. Asian Pac J Cancer Prev 2018;19:1411-1413.

95. Miftahussurur M, Yamaoka Y. Appropriate first-line regimens to combat Helicobacter pylori antibiotic resistance: an Asian perspective. Molecules 2015;20:6068-6092.

96. Hu Y, Zhang M, Lu B, Dai J. Helicobacter pylori and antibiotic resistance, a continuing and intractable problem. Helicobacter 2016;21:349-363.

97. Fallone CA, Chiba N, van Zanten SV, et al. The Toronto con- sensus for the treatment of Helicobacter pylori infection in adults. Gastroenterology 2016;151:51-69.

98. Jung YS, Kim EH, Park CH. Systematic review with metaanalysis: the efficacy of vonoprazan-based triple therapy on Helicobacter pylori eradication. Aliment Pharmacol Ther 2017;46:106-114.

99. Malfertheiner P, Megraud F, O’Morain CA, et al. Management of Helicobacter pylori infection-the Maastricht V/Florence Consensus Report. Gut 2017;66:6-30.

100. Davenport ER, Sanders JG, Song SJ, Amato KR, Clark AG, Knight R. The human microbiome in evolution. BMC Biol 2017;15:127.

101. Sheh A, Fox JG. The role of the gastrointestinal microbiome in Helicobacter pylori pathogenesis. Gut Microbes 2013;4:505-531.

102. Abreu MT, Peek RM Jr. Gastrointestinal malignancy and the microbiome. Gastroenterology 2014;146:1534-1546.

103. Bik EM, Eckburg PB, Gill SR, et al. Molecular analysis of the bacterial microbiota in the human stomach. Proc Natl Acad Sci U S A 2006;103:732-737.

104. Schütte K, Malfertheiner P, Schulz C. What is the relevance of gastric microbiota beyond H. pylori? Curr Treat Options Gastroenterol 2019;17:619-627.

105. Yang I, Woltemate S, Piazuelo MB, et al. Different gastric microbiota compositions in two human populations with high and low gastric cancer risk in Colombia. Sci Rep 2016;6:18594.

106. Schulz C, Schütte K, Koch N, et al. The active bacterial assemblages of the upper GI tract in individuals with and without Helicobacter infection. Gut 2018;67:216-225.

107. Ferreira RM, Pereira-Marques J, Pinto-Ribeiro I, et al. Gastric microbial community profiling reveals a dysbiotic cancer-associated microbiota. Gut 2018;67:226-236.

108. Schulz C, Schütte K, Mayerle J, Malfertheiner P. The role of the gastric bacterial microbiome in gastric cancer: Helicobacter pylori and beyond. Therap Adv Gastroenterol 2019;12:1756284819894062.

109. Coker OO, Dai Z, Nie Y, et al. Mucosal microbiome dysbiosis in gastric carcinogenesis. Gut 2018;67:1024-1032.

110. Gao JJ, Zhang Y, Gerhard M, et al. Association between gut microbiota and Helicobacter pylori-related gastric lesions in a high-risk population of gastric cancer. Front Cell Infect Microbiol 2018;8:202.

111. Park CH, Lee AR, Lee YR, Eun CS, Lee SK, Han DS. Evaluation of gastric microbiome and metagenomic function in patients with intestinal metaplasia using 16S rRNA gene sequencing. Helicobacter 2019;24:e12547. 